\title{
Elevated Human Chorionic Gonadotropin
}

National Cancer Institute

\section{Source}

National Cancer Institute. Elevated Human Chorionic Gonadotropin. NCI Thesaurus. Code C136631.

A finding indicating elevated concentrations of human chorionic gonadotropin in the blood. 